\title{
Intercultural competency development of health professions students during study abroad in India
}

\author{
Claire A. Richards *, Ardith Z. Doorenbos \\ University of Washington, Seattle, Washington, United States
}

Received: April 20, 2016

Accepted: July 18, 2016

Online Published: August 2, 2016

DOI: $10.5430 /$ jnep.v6n12p89

URL: http://dx.doi.org/10.5430/jnep.v6n12p89

\begin{abstract}
Objective: Short-term international health-related study abroad seminars for health-professions students are increasingly popular because of a focus in higher education on global awareness and intercultural competency. This study describes a study abroad strategy to teach students intercultural communication skills and knowledge, and evaluated the effectiveness of a 3-week healthrelated study abroad program and intercultural competency curriculum in increasing skills and knowledge of health-profession students.

Methods: This was a mixed methods study, with a pretest-posttest, within-subjects design, and content analysis of student reflection journals. The curriculum was designed to increase students' sensitivity to different cultural worldviews and support attitudes such as curiosity and openness that lead to relational abilities such as flexibility and adaptability. Students completed the Intercultural Sensitivity Scale (ISS) and Intercultural Effectiveness Scale (IES) both 3 months prior to and immediately following the trip. Means and standard deviations were calculated and a paired $t$-test was performed.

Results: Qualitative analysis of students' reflections presented evidence of developing awareness of their own cultural worldview, openness to Indian culture, and the use of skills to develop intercultural competence. There was a non-statistically significant improvement in ISS and IES scores.

Conclusions: Students' reflections demonstrated personal growth through the acquisition of knowledge and skills needed for further intercultural competence development. Students indicated that the curriculum helped them make meaning out of their experiences. Short-term health-related study abroad seminars may help students develop self-awareness and cultural openness by providing theoretically based curriculum before departure and while in the host country, including structured reflections and cultural mentoring, engagement with locals, and a balance of challenge with support.
\end{abstract}

Key Words: Cultural competency/education, Cultural awareness, Educational exchange, Nursing education research, India, Transcultural nursing

\section{INTRODUCTION}

Health-related study abroad seminars for health-professions students at higher education institutions in the United States are growing in popularity because of an increasing focus on global awareness, intercultural competence, and diversity. ${ }^{[1-3]}$ Study abroad is thought to be a way to improve collaborative skills and increase the intercultural competency of health professionals, ${ }^{[3-7]}$ which is considered an important goal to improve the quality of health care received by diverse patient populations. ${ }^{\left[{ }^{8,9]}\right.}$ Intercultural competency is defined as knowledge, attitudes, and behavioral skills that support effective interaction in culturally diverse contexts..$^{[10,11]}$

Health-related study abroad seminars are frequently shortterm sessions in which faculty determines the curricula.

*Correspondence: Claire A. Richards; Email: claire7@uw.edu; Address: University of Washington, Seattle, Washington, United States. 
Many reports on health-related study abroad in different disciplines, particularly in nursing, describe benefits to participants in regards to cultural self-efficacy, ${ }^{[5,12]}$ cultural self-awareness and sensitivity, ${ }^{[3,7,12]}$ development of a global or multicultural perspective, ${ }^{[4,6,13,14]}$ personal development, ${ }^{[4,7,15-18]}$ and increased cultural competence. ${ }^{[6,12]}$ Programs report beneficial outcomes from study abroad periods as short as one ${ }^{[14]}$ or two weeks, ${ }^{[5,12,13]}$ or as long as 12 weeks. ${ }^{[4,7,15]}$ Health-related study abroad programs, however, generally lack specific curricula designed to support intercultural competency development while abroad, ${ }^{[3-5,7,12,13,16,17]}$ although some programs include culturally specific information. ${ }^{[4,5,13,16]}$

Generally short-term study-abroad programs have been criticized for being ineffective and encouraging stereotypes of host cultures. ${ }^{[19]}$ Furthermore, studies in higher education have reported that while students often report being transformed by their study-abroad experiences, they often do not make gains in intercultural competence without guided reflections on their experiences. ${ }^{[20,21]}$ Guided reflections, often not included in study-abroad curricula, help students reflect on their experiences and become more self-aware, less judgmental, and more flexible. ${ }^{[22]}$ Short-term international health seminars may thus miss opportunities to develop the intercultural competence of health-professions students and may even inadvertently promote ethnocentrism, or the idea that one's own cultural worldview is central to all reality. ${ }^{[10]}$

For this short-term international health seminar, the intercultural competency curriculum and qualitative analysis was based on the theoretical models of Bennett ${ }^{[23]}$ and Deardorff, ${ }^{[24]}$ which both emphasize the internal changes necessary for effective intercultural interaction. Developing intercultural competence is a process of "increasing cultural self-awareness; deepening understanding of the experiences, values, perceptions, and behaviors of people from diverse cultural communities; and expanding the capability to shift cultural perspective and adapt behavior to bridge across cultural differences". [21]

Bennett's developmental model of intercultural sensitivity (DMIS) describes six stages of development from an ethnocentric perspective to an ethnorelative perspective; ${ }^{[23]}$ this is a shift from experiencing cultural difference as difficult to enjoyable, and inevitable. ${ }^{[10]}$ Deardorff's ${ }^{[24]}$ process model of intercultural competence (PMIC) begins with requisite attitudes toward other cultures, including respect, openness, curiosity, and discovery. According to Deardorff, the development of these attitudes moves the individual toward a deep understanding and knowledge of the impact of culture, others' worldviews, and knowledge of one's own culture, as well as toward skills such as listening, observation, and analysis. In Deardorff's model, the individual will then undergo internal changes in relational abilities such as adaptability, flexibility, and empathy and will incorporate a view of ethnorelativity. The development of these relational abilities is viewed as more important than learning culturally specific knowledge for behaving effectively in interpersonal interactions. ${ }^{[25]}$

The purpose of this study was to evaluate the effectiveness of a 3-week health-related study-abroad program and intercultural curriculum in India in increasing health professions students' intercultural competency and describe the students' development of intercultural skills and knowledge and their experience with the curriculum, as discovered in their written reflections. This study reports on the use of the DMIS and PMIC theories to form the basis for the development and evaluation of the intercultural competency curriculum.

\section{METHODS}

This was a mixed methods study, using a within-subject design with a pretest and posttest and directed content analysis of reflection journals. The study received exempt status through the Internal Review Board (IRB) at the University of Washington. Students who were to participate in the study-abroad program in India were given information about the research study during a group meeting. They were informed that research participation was optional and that consent could be withdrawn at any time. Students signed consent forms if they wished to participate. Participation in the research study included completing a posttest; all other components of this study (such as the pretest, which guided completion of a personal development plan; the reflection journals; and participation in group discussion) were required components of the program curriculum. The participants were informed that sharing their reflection journals for study purposes was not required to participate in the research. Eighteen of the 19 students in the program agreed to participate. Ten of the 18 students gave permission for the study to use their reflection journals. No incentives were given for participation in this study.

\section{METHOD}

\subsection{Setting and participants}

Participating students attended a 3-week course in India that focused on health and health care challenges in a developing and low-income country. The course included cultural experiences at three cities in the north and clinical rotations at two hospitals in the south (including one private and one public hospital). Rotations at the clinical sites included community health, psychology, family medicine, rehabilitation, surgery, medical surgery ward, labor and delivery, pediatrics, 
emergency department, internal medicine, and pharmacy.

The course was an elective health-related study abroad seminar in India entitled "Health in the Context of Culture". Students included both undergraduates with declared intentions to pursue degrees in nursing, medicine, or health-related disciplines and graduate students of nursing, pharmacy, and rehabilitation science (see Table 1 for demographic information).

Table 1. Demographic Characteristics $(\mathrm{N}=18)$

\begin{tabular}{lll}
\hline Characteristic & N & \% \\
\hline Age & & \\
$\quad$ <20 years & 3 & 16.7 \\
20-29 years & 14 & 77.8 \\
$\quad$ 30-39 years & 1 & 5.6 \\
Female & 17 & 94.4 \\
Race/Ethnicity & & \\
$\quad$ White & 10 & 55.6 \\
$\quad$ Other racial groups & 8 & 44.4 \\
Identify as Bicultural & & \\
$\quad$ Yes & 4 & 22.2 \\
$\quad$ No & 14 & 77.7 \\
Years lived outside of the United States & & \\
$\quad$ None & 15 & 83.3 \\
5 or more & 3 & 16.7 \\
Educational Program & & \\
$\quad$ Undergraduate, premedicine & 4 & 22 \\
$\quad$ Undergraduate, prenursing & 5 & 27.7 \\
$\quad$ Undergraduate, health career undecided & 1 & 5.6 \\
$\quad$ Graduate student, nursing & 2 & 11.1 \\
$\quad$ Graduate student, pharmacy & 5 & 27.7 \\
$\quad$ Graduate student, rehabilitation science & 1 & 5.6 \\
\hline
\end{tabular}

\subsection{Intercultural competency curriculum}

Faculty accompanying students on the trip developed and delivered the intercultural competency curriculum. The curriculum included a predeparture session, personal development plan based on individual results from pretests, reflection journals, and facilitated group sessions. This curriculum emphasized internal processing of experiences through structured reflection journals and facilitated group sessions. The DMIS $^{[23]}$ and the PMIC ${ }^{[24]}$ were integrated in the reflection journals and through an emphasis on the development of relational abilities. All students received the intercultural competency curriculum and completed pretests; participation in the study involved the additional step of completing the posttests.

\subsubsection{Predeparture session}

A single half-day predeparture session was delivered 3 months in advance of departure during the end of the Spring quarter. The 3-month timing of the session was required because many students were leaving the campus during summer quarter prior to departure to India. All students completed the Intercultural Effectiveness Scale (IES) and Intercultural Sensitivity Scale (ISS) prior to this meeting. ${ }^{[26,27]}$ The meaning of culture was discussed and the dimensions of intercultural competencies measured by the IES were defined. Both students and faculty engaged in role-plays to show the presence and absence of intercultural effectiveness in situations they would be likely to encounter in India. In an exercise to increase self-awareness of personal worldviews, students explored their own values, beliefs, and experiences and shared with the group. A faculty member trained to administer the IES distributed the results to students after the students evaluated themselves on each of the IES domains. Results were contextualized in a 22-page individual feedback report developed by the Kozai Group that includes the scores, explanations of scores, and a template for a personal development plan. ${ }^{[27]}$ Each student then developed a plan for improving one of the competencies of their own choosing. Two students who were unable to attend this predeparture session received the session from faculty via telephone.

\subsubsection{Guided reflections}

As a standard part of the curriculum, students were given journals with activities ${ }^{[28]}$ and guided reflections. These were designed to address different competencies in the Association of American Colleges \& Universities' (AACU's) Intercultural Knowledge and Competence VALUE Rubric in Table $2^{[29]}$ and to stimulate students to develop intercultural knowledge and skills as described by Deardorff. ${ }^{[24]}$ The VALUE rubric, developed by faculty experts across the United States, combines the stages of the DMIS described by Bennett ${ }^{[10]}$ with the intercultural competency knowledge and skills in the PMIC described by Deardorff. ${ }^{[24]}$ The rubric addresses the skills of cultural self-awareness, knowledge of cultural worldview frameworks, empathy, and verbal and nonverbal communication and the attitudes of curiosity and openness.

Prompts for reflections aimed to stimulate students to gain greater cultural self-awareness through reflection on their own perspective and worldview, to be curious about cultural frameworks that might underlie behavior or ideas that they don't understand, and to plan for either behavioral changes in interpersonal interactions with others or internal changes in attitudes, knowledge, skills, or flexibility. The reflection prompts were adapted from a service learning reflection journal. ${ }^{[30]}$

At the end of each week of the program, students critically evaluated their own intercultural development using a version of the AACU's Intercultural Knowledge and Competence VALUE Rubric adapted by Calahan ${ }^{[28]}$ at the Center for Intercultural Excellence. This adapted version includes just three 
of the original four categories of intercultural development. On five occasions, students and faculty met to discuss and reflect on their experiences as a group. At the end of the trip in India, students completed a posttest with the IES and ISS.

\subsection{Instruments}

The Intercultural Effectiveness Scale (IES) measures three dimensions of intercultural competency: (a) continuous learning, (b) intercultural engagement, and (c) hardiness. ${ }^{[27,31]}$ The IES consists of 52 items with a 5-point Likert format ranging from 1 (strongly disagree) to 5 (strongly agree). The overall IES score ranges between 52 and 250, with higher scores indicating greater intercultural competency. The dimension "continuous learning" includes 19 items and a sample item is "I'm aware of my interpersonal style and can easily describe it to others". ${ }^{[31]}$ The dimension "intercultural engagement" includes 15 items and a sample item is "I like to figure out why people do the things they do". The dimension "hardiness" includes 18 items and a sample item is "I can always find something good in any situation". The scale has acceptable reliability $(\alpha=.85)$ and has face and content validity. ${ }^{[32]}$

Table 2. AACU's Intercultural Knowledge and Competence VALUE Rubric

\begin{tabular}{|c|c|c|c|c|}
\hline \multirow{2}{*}{ Domain } & \multirow{2}{*}{$\begin{array}{l}\text { Capstone } \\
4\end{array}$} & \multicolumn{2}{|l|}{ Milestones } & \multirow{2}{*}{$\begin{array}{l}\text { Benchmark } \\
2 \\
\end{array}$} \\
\hline & & 3 & 2 & \\
\hline $\begin{array}{l}\text { Knowledge } \\
\text { Cultural self- } \\
\text { awareness }\end{array}$ & $\begin{array}{l}\text { Articulates insights into } \\
\text { own cultural rules and } \\
\text { biases (e.g. seeking } \\
\text { complexity; aware of how } \\
\text { her/his experiences have } \\
\text { shaped these rules, and how } \\
\text { to recognize and respond to } \\
\text { cultural biases, resulting in } \\
\text { a shift in self-description.) }\end{array}$ & $\begin{array}{l}\text { Recognizes new } \\
\text { perspectives about own } \\
\text { cultural rules and biases } \\
\text { (e.g. not looking for } \\
\text { sameness; comfortable } \\
\text { with the complexities that } \\
\text { new perspectives offer.) }\end{array}$ & $\begin{array}{l}\text { Identifies own cultural rules and } \\
\text { biases (e.g. with a strong preference } \\
\text { for those rules shared with own } \\
\text { cultural group and seeks the same in } \\
\text { others.) }\end{array}$ & $\begin{array}{l}\text { Shows minimal awareness } \\
\text { of own cultural rules and } \\
\text { biases (even those shared } \\
\text { with own cultural group(s)) } \\
\text { (e.g. uncomfortable with } \\
\text { identifying possible cultural } \\
\text { differences with others.) }\end{array}$ \\
\hline $\begin{array}{l}\text { Skills } \\
\text { Empathy }\end{array}$ & $\begin{array}{l}\text { Interprets intercultural } \\
\text { experience from the } \\
\text { perspectives of own and } \\
\text { more than one worldview } \\
\text { and demonstrates ability to } \\
\text { act in a supportive manner } \\
\text { that recognizes the feelings } \\
\text { of another cultural group. }\end{array}$ & $\begin{array}{l}\text { Recognizes intellectual and } \\
\text { emotional dimensions of } \\
\text { more than one worldview } \\
\text { and sometimes uses more } \\
\text { than one worldview in } \\
\text { interactions }\end{array}$ & $\begin{array}{l}\text { Identifies components of other } \\
\text { cultural perspectives but responds in } \\
\text { all situations with own worldview. }\end{array}$ & $\begin{array}{l}\text { Views the experience of } \\
\text { others but does so through } \\
\text { own cultural worldview. }\end{array}$ \\
\hline $\begin{array}{l}\text { Attitudes } \\
\text { Curiosity }\end{array}$ & $\begin{array}{l}\text { Asks complex questions } \\
\text { about other cultures, seeks } \\
\text { out and articulates answers } \\
\text { to these questions that } \\
\text { reflect multiple cultural } \\
\text { perspectives. }\end{array}$ & $\begin{array}{l}\text { Asks deeper questions } \\
\text { about other cultures and } \\
\text { seeks out answers to these } \\
\text { questions. }\end{array}$ & $\begin{array}{l}\text { Asks simple or surface questions } \\
\text { about other cultures. }\end{array}$ & $\begin{array}{l}\text { States minimal interest in } \\
\text { learning more about other } \\
\text { cultures. }\end{array}$ \\
\hline $\begin{array}{l}\text { Attitudes } \\
\text { Openness }\end{array}$ & $\begin{array}{l}\text { Initiates and develops } \\
\text { interactions with culturally } \\
\text { different others. Suspends } \\
\text { judgment in valuing her/his } \\
\text { interactions with culturally } \\
\text { different others. }\end{array}$ & $\begin{array}{l}\text { Begins to initiate and } \\
\text { develop interactions with } \\
\text { culturally different others. } \\
\text { Begins to suspend } \\
\text { judgment in valuing her/his } \\
\text { interactions with culturally } \\
\text { different others. }\end{array}$ & $\begin{array}{l}\text { Expresses openness to most, if not } \\
\text { all, interactions with culturally } \\
\text { different others. Has difficulty } \\
\text { suspending any judgment in her/his } \\
\text { interactions with culturally different } \\
\text { others, and is aware of own } \\
\text { judgment and expresses a } \\
\text { willingness to change. }\end{array}$ & $\begin{array}{l}\text { Receptive to interacting } \\
\text { with culturally different } \\
\text { others. Has difficulty } \\
\text { suspending any judgment in } \\
\text { her/his interactions with } \\
\text { culturally different others, } \\
\text { but is unaware of own } \\
\text { judgment. }\end{array}$ \\
\hline
\end{tabular}

Note. Excerpted with permission from "VALUE: Valid Assessment of Learning in Undergraduate Education.” Copyright 2015 by the Association of American Colleges and Universities. http://www.aacu.org/value.

The Intercultural Sensitivity Scale (ISS) measures five affective factors of intercultural competency. ${ }^{[26]}$ The ISS is a 24-item scale with a 5-point Likert format ranging from 1 (strongly disagree) to 5 (strongly agree) that bases its statements on 5 factors: (a) interaction engagement (b) respect for cultural differences, (c) interaction confidence, (d) in- teraction enjoyment, and (e) interaction attentiveness. The overall score of the ISS ranges between 24 and 120 with higher scores indicating greater intercultural competency. The factor "interaction engagement" includes 7 items and a sample item is "I enjoy interacting with people from different cultures". The factor "respect for cultural differences" 
includes 6 items and a sample item is "I respect the ways people from different cultures behave". The factor "interaction confidence" includes 5 items and a sample item is "I' $m$ pretty sure of myself in interacting with people from different cultures." The factor "interaction enjoyment" includes three items and a sample item is "I often get discouraged when I am with people from different cultures". And the factor "interaction attentiveness" includes 3 items and a sample item is "I am very observant when interacting with people from different cultures". The ISS has acceptable reliability ( $\alpha=$ .86 ), with good predictive validity and concurrent validity with five other related instruments.

\subsection{Analysis}

Means and standard deviations were calculated for each overall scale and all subscales. A paired $t$-test was performed using pre- and posttests for the overall scores for the IES and ISS. Journal entries were analyzed by the first author using the qualitative method of directed content analysis. ${ }^{[33]}$ The
Intercultural Knowledge and Competence VALUE Rubric ${ }^{[29]}$ was used as a coding frame to guide analysis. Included in this analysis were different levels of cultural self-awareness, empathy, curiosity, and openness, which are four of the six skills and attitudes defined in the original VALUE rubric. For rigor of the analysis, the second author reviewed all of the first author's codes and analysis.

\section{QUANTITATIVE RESUlts}

A paired-samples $t$-test was conducted to compare the IES and ISS pre- and posttests. There was no significant difference in the scores from the IES pretest $(\mathrm{M}=3.73, \mathrm{SD}=$ $0.26)$ to the posttest $(\mathrm{M}=3.8, \mathrm{SD}=0.24 ; t(17)=1.09, p=$ .290). Nor was there a significant difference in the scores from the ISS pretest $(\mathrm{M}=97.78, \mathrm{SD}=8.15)$ to the posttest $(\mathrm{M}=98.75, \mathrm{SD}=8.64 ; t(17)=0.41, p=.687)$. We did not find statistically significant differences, although students showed some increase in overall scores in both IES and ISS (see Table 3).

Table 3. Intercultural effectiveness survey and intercultural sensitivity scale results

\begin{tabular}{|c|c|c|c|c|}
\hline \multirow{2}{*}{ Scale and Subscales } & \multicolumn{2}{|c|}{ Pretest $(N=18)$} & \multicolumn{2}{|c|}{ Posttest $(N=18)$} \\
\hline & $M$ & $S D$ & $M$ & $S D$ \\
\hline \multicolumn{5}{|l|}{ Intercultural Effectiveness Survey } \\
\hline Overall & 3.73 & .26 & 3.81 & .24 \\
\hline Continuous Learning & 4.09 & .23 & 4.17 & .25 \\
\hline Interpersonal Engagement & 3.45 & .41 & 3.46 & .44 \\
\hline Hardiness & 3.64 & .41 & 3.73 & .36 \\
\hline \multicolumn{5}{|l|}{ Intercultural Sensitivity Survey } \\
\hline Overall & 97.78 & 8.15 & 98.75 & 8.64 \\
\hline Interaction Engagement & 29.22 & 2.69 & 30.44 & 3.05 \\
\hline Respect for Cultural Differences & 26.83 & 2.18 & 27.08 & 2.23 \\
\hline Interaction Confidence & 17.44 & 2.60 & 16.50 & 2.20 \\
\hline Interaction Enjoyment & 12.56 & 1.38 & 12.44 & 1.79 \\
\hline Interaction Attentiveness & 11.72 & 1.64 & 12.28 & 2.14 \\
\hline
\end{tabular}

\section{QUALITATIVE RESULTS}

The qualitative analysis assessed levels of cultural selfawareness, curiosity, openness, and empathy, as defined in the VALUE rubric excerpted in Table 2. ${ }^{[29]}$ All descriptions of intercultural competency levels in the following sections are from this rubric.

\subsection{Cultural self-awareness}

Most participants' journal entries demonstrated cultural selfawareness at Level 2. At this level of self-awareness, individuals are able to identify their own cultural rules and biases but have a preference for their own cultural rules. The journal entry below captures this level of development:

Riding on a train which was so jam packed with people and bodies very close together made me wonder how people live like this every day. I felt very uncomfortable and wondered if I would ever get used to it. This experience taught me that personal space, or a "personal bubble" is not as important in this cultural context the same way that it is valued in the U.S. - Participant 1
This participant questioned whether or not she would be able to adapt to Indian culture because she strongly preferred her own cultural norms regarding personal space. However, this participant used knowledge of cultural frameworks to make meaning out of her discomfort and recognized that adaptation would require a different attitude toward personal space. Some participants had difficulty recognizing biases rooted in their own cultural perspectives and struggled to suspend judgment. Such biases represent a challenge in the 
development of cultural self-awareness.

\subsection{Curiosity}

In Level 2 of curiosity, a person asks simple or surface questions about another culture whereas in Level 3, a person asks deeper questions and seeks out answers. Half of the participants expressed curiosity at either Level 2 or 3 on the VALUE rubric. However, the remaining participants made assumptions or generalizations to explain their experiences rather than asking questions. A few participants made reflective statements that indicated a move from Level 2 to Level 3 of curiosity:

I was surprised to see that I was able to define my own cultural beliefs and values and that I often preferred my culture's standards. I think this is due to the fact that I didn't fully understand the deeper roots of these behaviors. It has led me to ask deeper questions about the culture. For example, does India not see value in time because they have been accustomed to a lifestyle of lax living and simple things? All the while, America is always trying to do more and is on the constant pursuit of trying to be successful. Does the Indian culture view success and happiness in a different way than we do? -Participant 5

In the above quote, the participant asks deeper questions about Indian culture (Level 3), connecting what she observes about the value of time to underlying values about success and happiness. The use of the words "lax living" suggests that the participant has difficulty suspending judgment about an unstated behavior that the participant had observed. This might be viewed as a lack of openness, although the student is simultaneously trying to understand this discomfort by asking questions about deeper underlying values of Indian and American cultures. Participants demonstrated Level 2 curiosity by asking more surface or simple questions about the culture:

Although the waitress and attendants were very kind, the service was significantly slower than anything I have ever experienced in the States... in the U.S. service is analogous with speed. -Participant 6

However, students often made assumptions or generalizations without considering the counterfactual or alternative ways to interpret or explain their experiences.

The locals definitely don't view stray dogs the same way that I do. While they ignore them, my heart sinks every time I see one... - Participant 7

As an example of a counterfactual, instead of assuming that one's conclusions are correct, a participant might instead write, "It seems to me that the locals don't value the life of dogs like I do, but perhaps there is another explanation." While participants tended to generalize, they also tempered their assumptions with words such as "it seems like" or "I wonder if" even when they did not suggest alternative perspectives.

\subsection{Openness}

Participants demonstrated Level 2 cultural openness, defined as expressing openness to most interactions, still having difficulty suspending judgment, and yet being aware of judgment and desiring to change.

During our visit to the dean's office, the [head of] cardiology was speaking to all of us. All the while, other staff were speaking amongst each other and the dean was speaking on her phone... I was slightly annoyed because I felt that it was disrespectful to both the listeners and speakers to be talked over within a room. This has taught me that there is not much behavioral consideration for others or that they express consideration for each other in different ways. It has taught me that I have a little more resistance to being open/immersed in a culture than I had previously thought. - Participant 5

This participant was aware of resistance to the culture, but she wished to be more open. Her position was self-reflective and insightful - and a necessary step for further development. Other students were unaware of having judgment:

Since moms usually play the central role in a child's life here, it was nice to see the dads come into the picture. It showed that they wanted to help instead of piling everything on the mom... There are always exceptions and make sure that both parents are involved in the future. -Participant 7

This participant saw an interaction that challenged her assumptions of gender roles in Indian culture, but still concluded that her observation was an exception to the norm and reserved judgment about it.

\subsection{Empathy}

Empathy, as defined by the VALUE rubric, involves interpreting intercultural experiences in more than one worldview, 
recognizing the emotions of persons from another culture, and responding with supportive behavior. ${ }^{[29]}$ For the most part, we were unable to code different levels of empathy in the participants' reflections. This may be because participants often did not report their own behavior, but rather their observations of others. However, one participant who wrote about a clinical experience demonstrated a mix of different intercultural competency skills, including openness, curiosity, and empathy.

There were a couple of [Indian] nursing students assigned to us... one of our students went to labor and delivery while the rest of us were interested in seeing the wards. The students seemed kind of alarmed... [They] were very set on following the instructions passed down to them and they seemed to get worried when one of us proposed another idea. At first this really confused me. I continued to question why do they want us to stick all together when there is so much to see in pediatrics? It was almost frustrating that I did not feel I had the freedom to explore personally what I personally wanted to. As I continue thinking about this experience, I realize that this may be a cultural awareness that I am not used to experiencing. The students were given directions from someone superior and if they did not follow them it may reflect poorly on them. Overstepping or voicing opinions is probably something they are not used to... Not being able to freely choose where I am at one time is not an environment I feel completely comfortable with ... [In the future I would] probably just listen to directions more so that I don't offend the students or make them feel like they are not following directions from their superior. Since I am observing in pediatrics again, my goal is to observe or ask questions about power and direction to these students to develop a better understanding of this cultural norm. -Participant 8

According to the AACU rubric, Level 3 empathy involves recognizing different worldviews and perspectives and using more than one worldview in interactions, while Level 2 empathy involves responding to all situations with primarily one worldview. ${ }^{[29]}$ The participant quoted above demonstrated openness to responding differently in the future and behaving appropriately within the cultural context she was in, while preferring her own norms. The participant became aware of cultural differences between India and the United States in that India has a larger power distance: there is an Published by Sciedu Press acceptance of inequality of power, and communication is top-down, whereas in the US there is an expectation that employees and managers consult each other and share information freely. ${ }^{[34]}$ On recognizing the cultural difference, she expressed curiosity by asking deeper questions about the culture and expressing a commitment to seeking answers to her questions from the Indian nursing students.

\subsection{Response to the Curriculum}

Participants expressed both in conversation and in written reflections that the guided reflections were valuable in developing self-awareness and that the curriculum gave them a language with which to understand their experiences. Learning about intercultural competencies and theories gave these students a framework to understand their emotional responses as a normal part of the difficulty in adapting to another culture, and this understanding allowed students to confront daily challenges and open themselves to further intercultural development.

My expectations for this trip were to be open, receptive and accepting of all behaviors as my initial reaction. However, as I reflected and pondered about my experiences each night (and as we had our group discussions), I slowly began to realize that I was confused and questioned the culture a lot. Often times, I became frustrated and somewhat rejected some of their mannerisms such as: cutting in lines, the persistent attempts to sell things I've expressed no interest in the constant request for money, etc. As time went by, however, I began to see other aspects of the culture that I enjoyed such as their hospitality, resourcefulness, etc., and that allowed me to begin to assess the roots of the culture that I initially rejected. -Participant 5

\section{Discussion}

When changes in intercultural competence were measured using quantitative instruments, no statistically significant improvements were noted. The lack of statistical significance may have been because the study was underpowered due to the small sample size. Results from the qualitative analysis indicated that students expressed knowledge and skills in self-awareness of their own cultural worldview and openness, while they tended to express curiosity less often and to make generalizations and assumptions about their experiences. Guided reflections that directly ask students to consider alternative explanations for their observations may be beneficial to the development of curiosity. It was difficult to assess empathy because students typically wrote about the 
behavior of others rather than their own. While it was not possible to assess the knowledge skills participants had prior to their exposure to the curriculum, students both said and wrote that self-reflection and knowledge of cultural theories were helpful in making meaning and remaining open to their intercultural experiences.

Guided group reflections on intercultural experiences have been found to be critical for intercultural competency development. ${ }^{[21]}$ However, during the 3-week seminar, group reflections intended to be daily were reduced to five sessions total due to external constraints and student fatigue. For example, on two evenings the group reflections were cancelled in favor of planned events where students engaged with local nursing students. This reduced the amount of in-country cultural mentoring, yet provided an opportunity to interact with locals in a different setting, also critical for intercultural development.

The intercultural development of students in this program may have been limited by the amount of engagement the students had with locals because they were primarily spending their free time and residing with other students in the seminar. A large study on intercultural learning of students studying abroad found that students who spent most of their study-abroad time with other U.S. nationals had less learning than those who spent more time with locals. ${ }^{[22]}$ This is because students can remain in a cultural "bubble" or "island" if not engaged in the day-to-day life of locals. ${ }^{[21]}$ However, Sanford has argued that students learn best with a balance between challenge and support, and that if the challenge is too great, then students will withdraw from the learning. ${ }^{[22,35]}$ This suggests that students in this seminar who had minimal knowledge of the host culture, a lack of proficiency in the local language, and limited international traveling experience, may have needed a buffered travel experience in order to support their development.

This study has several limitations. This study included a small convenience sample $(\mathrm{N}=18)$ from a single university; and results are not generalizable to other programs. Furthermore, the qualitative analysis is based only on journal entries, and we were unable to ask follow-up questions to confirm interpretations. In addition, students developed personal development plans based on their pretest scores. The curriculum's emphasis on these subscales could communicate to students that there is a "right" and "wrong" answer; thus social desirability could confound results. However, the primary purpose of the program was to benefit students, and giving students feedback on their intercultural competency was considered an essential aspect of the curriculum. Mean- while, the challenge of encountering culturally different others may have negatively affected students' self-perceptions of intercultural competency, which would decrease our ability to detect improvements.

\section{Conclusions}

We examined the innovative use of an intercultural competency curriculum within a short health-related seminar. This curriculum included a half-day pre-departure seminar facilitated by a feedback report on the Intercultural Effectiveness Survey results and a template for a personal development plan provided by the Kozai group. ${ }^{[27]}$ In addition, students wrote in journals on a daily basis in response to prompts intended to increase student sensitivity to cultural worldviews and relational abilities such as flexibility and openness. Students also evaluated their own learning using the AACU Intercultural Knowledge and Competence VALUE Rubric, an online tool available to educators. ${ }^{[29]}$ Short, buffered seminars are unlikely to result in significant intercultural competence gains-and in fact, no statistically significant, measurable improvement in competency scores was found in this study. However, students' reflections demonstrated some progression in development of knowledge and skills, and student responses to exercises and group discussion indicated that they found the curriculum helpful in making meaning of their experiences. An intentional approach to incorporating intercultural development activities with guided and group reflection may allow students to gain basic skills and language about cultural competency to take forward in life-long learning and development.

\section{ACKNOWLEDGEMENTS}

Research reported in this publication was supported by the National Institute of Nursing Research of the National Institutes of Health under award number \#K24NR015340 and by the National Center for Advancing Translational Sciences, National Institutes of Health, through Grant TL1 TR000422. The content is solely the responsibility of the authors and does not necessarily represent the official views of the NIH.

We would like to thank Ryan A. Richards for his contribution to this study by helping to develop the curriculum, critically reviewing the manuscript, and serving with us as faculty on the India Exploration Seminar.

Tandem Editing LLC provided professional editing for this article.

\section{CONFlicts of INTEREST Disclosure}

The author declares that there is no conflict of interest. 


\section{REFERENCES}

[1] Cisneros RM, Jawaid SP, Kendall DA, et al. International practice experiences in pharmacy education. Am J Pharm Educ [Internet]. 2013 Nov 20; 77(9): 188.

[2] Kelleher S. Perceived benefits of study abroad programs for nursing students: an integrative review. J Nurs Educ [Internet]. 2013 Nov 22; 52(12): 690-5. PMid: 24256000. Available from: http://www.healio.com/nursing/journals/jne/2013-1 2-52-12/\%7Bdd2abda3-3866-4fbe-98f8-b1beb97e15dc\%7D /perceived-benefits-of-study-abroad-programs-for-n ursing-students-an-integrative-review.pdf

[3] Duffy ME, Farmer S, Ravert P, et al. International community health networking project: two year follow-up of graduates. Int Nurs Rev [Internet]. 2005 Feb 24; 52(1): 24-31. PMid: 15725273. Available from: http://onlinelibrary.wiley.com/doi/10.1111/ j.1466-7657.2004.00252.x/abstract

[4] Thompson K, Boore J, Deeny P. A comparison of an international experience for nursing students in developed and developing countries. Int J Nurs Stud [Internet]. 2000 June 29; 37(6): 481-92.

[5] Larsen R, Reif L. Effectiveness of Cultural Immersion and Culture Classes for Enhancing Nursing Students Transcultural Self-Efficacy. J Nurs Educ [Internet]. 2011; 50(6): 350-4.

[6] Edmonds ML. An integrative literature review of study abroad programs for nursing students. Nurs Educ Perspect [Internet]. 2012 March 26; 33(1): 30-4. PMid: 22416538. Available from: http://www.ncbi.nlm.nih.gov/linkout/pmliblink . $c g i$ ? $i d=22416538 \& l i b=u w a s h$

[7] Greatrex-White S. Uncovering study abroad: foreignness and its relevance to nurse education and cultural competence. Nurse Educ Today [Internet]. 2008 Oct 13; 28(5): 530-8. PMid: 17931751. Available from: http://www.nurseeducationtoday.com/article/ S0260-6917(07)00136-0/abstract

[8] Saha S, Beach MC, Cooper LA. Patient centeredness, cultural competence and healthcare quality. J Natl Med Assoc [Internet]. 2008 Nov 26; 100(11): 1275-85. PMid: 19024223 http://dx.doi.org /10.1016/S0027-9684(15) 31505-4

[9] Sargent SE, Sedlak CA, Martsolf DS. Cultural competence among nursing students and faculty. Nurse Educ Today [Internet]. 2005 March 30; 25(3): 214-21. PMid:15795024 http://dx .doi.org/1 $0.1016 /$ j.nedt . 2004.12.005

[10] Bennett MJ. Towards ethnorelativism: a developmental model of intercultural sensitivity. In: Paige RM, editor. Education for the Intercultural Experience. Yarmouth, ME: Intercultural Press; 1993.

[11] Chen G, Starosta WJ. A review of the concept of intercultural awareness. Hum Commun [Internet]. 1999; 2(1): 27-54. Available from: http://digitalcommons.uri.edu/cgi/viewcon tent.cgi?article=1036\&context=com_facpubs

[12] St Clair A, McKenry L. Preparing culturally competent practitioners. J Nurs Educ [Internet]. 1999 Aug 7; 38(5): 228-34. PMid:10438097

[13] Walsh LV, DeJoseph J. "I saw it in a different light": international learning experiences in baccalaureate nursing education. J Nurs Educ [Internet]. 2003; 42(6): 266-72. PMid:12814217

[14] Pross E. International nursing students: a phenomenological perspective. Nurse Educ Today [Internet]. 2003; 23(6): 396-403. http: //dx.doi.org/10.1016/S0260-6917(03)00066-2

[15] Greatrex-White S. A way of seeing study abroad: narratives from nurse education. Learning in Health \& Social Care [Internet]. 2007; 6(3): 134-44. http://dx.doi.org/10.1111/j.1473-6861.20 $07.00157 . \mathrm{x}$

[16] DeDee LS, Stewart S. The effect of student participation in international study. J Prof Nurs [Internet]. 2003 Sept 10; 19(4): 237-42. http: //dx.doi.org/10.1016/S8755-7223(03)00086-3
[17] Zorn CR. The long-term impact on nursing students of participating in international education. J Prof Nurs [Internet]. 1996; 12(2): 106-10. http://dx .doi .org/10.1016/S8755-7223(96)80056-1

[18] Fallowfield L, Jenkins V, Farewell V, et al. Efficacy of a Cancer Research UK communication skills training model for oncologists: a randomised controlled trial. Lancet [Internet]. 2002 March 7; 359(9307): 650-6. http://dx.doi.org/10.1016/S0140-673 6(02) 07810-8

[19] Wynveen CJ, Kyle GT, Tarrant MA. Study Abroad Experiences and Global Citizenship: Fostering Proenvironmental Behavior. J Stud Int Educ [Internet]. 2012; 16(4): 334-52. http://dx.doi .org/10.11 $77 / 1028315311426782$

[20] Paige RM, Vande Berg M. Why students are and are not learning abroad. In: Student learning abroad: What our students are learning, what they're not, and what we can do about it. [Internet]. Sterling, VA: Stylus Publishing, LLC; 2012; 30 p. PMid: 12900187 Available from: http: //www.nurseeducationtoday.com/article/ S0260-6917 (05) 00147-4/pdf

[21] Hammer MR. The intercultural development inventory: A new frontier in assessment and development of intercultural competence. In: Vande Berg M, Paige RM, Lou KH, editors. Student Learning Abroad. [Internet]. Sterling, VA: Stylus Publishing; 2012. Available from: https://idiinventory.com/wp-content/uploa ds/2013/08/HAMMER-STUDY-ABROAD-ARTICLE-2012.pdf

[22] Vande Berg M, Connor-Linton J, Paige RM. The Georgetown consortium project: Interventions for students learning abroad. Frontiers [Internet]. 2009; 18: 1-75. Available from: http://studyabroad.isp.msu.edu/research/Resea $r$ ch-VandeBerg-Georgetown.pdf

[23] Bennett MJ. A developmental approach to training for intercultural sensitivity. Int J Intercult Relat [Internet]. 1986; 10(2): 179-96. http ://dx .doi.org/10.1016/0147-1767 (86)90005-2

[24] Deardorff DK. Identification and assessment of intercultural competence as a student outcome of internationalization. J Stud Int Educ [Internet]. 2006; 10(241): 241-66. http://dx.doi.org/10.1177 /1028315306287002

[25] Soule I. Cultural competence in health care: an emerging theory. ANS Adv Nurs Sci [Internet]. 2014; 37(1): 48-60. PMid:24469088 http://dx.doi.org/10.1097/ANS.0000000000000016

[26] Chen G, Starosta WJ. The development and validation of the intercultural sensitivity scale. Annual Meeting of the National Communication Association [Internet]. Seattle: U.S. Department of Education. 2000; 21 p. Available from: http://eric.ed.gov/?id=ED4475 25

[27] Kozai Group. The intercultural effectiveness scale (IES) [Internet]. Chesterfield (MO): Kozai Group; n.d. [cited 2016 April 3]. Available from: http://www.kozaigroup.com/intercultural -effectiveness-scale-ies/

[28] Calahan CA. Intercultural learning 101 study abroad: Center for Instructional Excellence; [Internet] n.d. [cited 2015 April 8]. 27 p. Available from: http://www.acenet.edu/news-room/Docume nts/Intercultural-Learning-101-IIA-June-2014.pdf

[29] Association of American Colleges \& Universities. Intercultural knowledge and competence VALUE rubric [Internet]. Washington: Association of American Colleges \& Universities, 2015 [cited 2016 March 30]. Available from: http://www.aacu.org/value/rub rics/intercultural-knowledge

[30] Sass M. Service learning reflection journal. In: Purdue University Learning and Service Engagement Series [Internet]. West Lafayette: Center for Instructional Excellence; 2013 [cited June 15, 2015]. Available from: http://docs.lib.purdue.edu/ 
[31] Kozai Group. The Intercultural Effectiveness Scale: Example statements from the IES Chesterfield, MO: Kozai Group; 2009 [cited 2016 July 15]. Available from: http://13258-presscdn-0-26.pagely.netdna-cdn.com/w p-content/uploads/2015/09/IESSampleStatements.pdf

[32] Mendenhall ME, Stevens MJ, Bird A, et al. Specification of the content domain of the intercultural effectiveness scale. Kozai Monogr Ser [Internet]. 2008; 1(3): 1-26.1. Available from: http://www.kozaigroup.com/wp-content/uploads/2 015/09/IESTechReport.pdf
[33] Hsieh HF, Shannon SE. Three approaches to qualitative content analysis. Qual Health Res [Internet]. 2005; 15(9): 127788. PMid:16204405 http://dx.doi.org/10.1177/104973230 5276687

[34] The Hofstede Center. What about India [Internet]. Helsinki, Finland: Itim International; n.d. [cited 2016 March 9]. Available from: http://geert-hof stede.com/india.html

[35] Sanford N. Self \& society: social change and individual development. New York, NY: Atherton Press; 1966. 